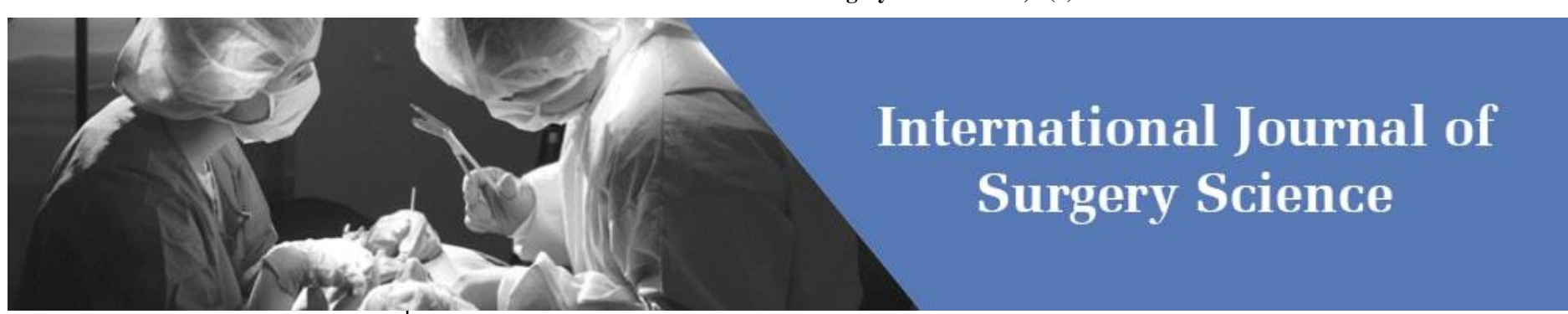

E-ISSN: 2616-3470

P-ISSN: 2616-3462

(C) Surgery Science

www.surgeryscience.com

$2019 ; 3(3): 313-317$

Received: 01-05-2019

Accepted: 05-06-2019

Dr. Ahmed Dawood Jasim

Ninavah Health Directorate, Iraq

Dr. Ali Abdul Qader Ahmed

Ninavah Health Directorate, Iraq

Dr. Muayad Aed Khaleel

Ninavah Health Directorate, Iraq

\section{Transcanalicular laser dacryocystorhinostomy as a recent approach for treating nasolacrima duct obstruction at Al-Mosul teaching centre}

\author{
Dr. Ahmed Dawood Jasim, Dr. Ali Abdul Qader Ahmed and Dr. Muayad \\ Aed Khaleel
}

DOI: $\underline{\text { https://doi.org/10.33545/surgery.2019.v3.i3f.187 }}$

\section{Abstract}

Background: Transcanalicular laser dacryocystorhinostomy (TCL- DCR) is a recent \& minimally invasive procedure used to bypass the nasolacrimal duct

Objective: The objective is to analyze the short term success rate, complications and causes of failure of this procedure of this case series study of 68 consecutive transcanalicular laser dacryocystorhinostomy procedures of 66 patients complaining of epiphora\& recurrent or chronic dacryocystitis due to nasolacrimal duct obstruction in our centre (AL Mosul Teaching Centre).

Patients and Methods: Sixty six patients with complete obstruction of NLD with age range (5-55) years were included in the study, underwent transcanalicular laser dacryocystorhinostomy in the period from October 2012-April 2013 at AL Mosul Teaching Centre. The procedure was performed under general anesthesia osteotomy was performed by transcanalicular diode laser and insertion a temporary stents, patients were followed up for 3-4 months to assess the outcome of the procedure.

Results: Epiphora was ceased and a patent NLD on irrigation in 55 out of 68 treated eyes this yields success rate of $81 \%$ at an average follow up time 3-4 months, results was (1) Swelling of the ipsilateral lower eyelid in 38 cases, (2) Postoperative adhesions developed in 11 patients and (3) Bruising in 8 cases. Conclusion: TCL-DCR is a recent modality to the developments in the field of lacrimal surgery at ALMosul Teaching Centre: it is minimally invasive and quick procedure yielding result comparable to classic DCR and better than other endoscopic DCR procedure.

Keywords: Nasolacrimal, comparable, procedure

\section{Introduction}

Dacryocystorhinostomy (DCR) is a surgical procedure indicated for treatment of lacrimal obstruction at the level of the lacrimal sac or nasolacrimal duct. It is based on the formation of a new opening between the nasal cavity and the lacrimal sac, enabling tears to bypass the site of obstruction. The result of a patent opening is the relief of epiphora and discharge. The oldest mention of lacrimal surgery is the Codex of Hammurabi from $1760 \mathrm{BC}$, which contains a reference to surgical treatment of lacrimal sac abscess and fistula. Later descriptions come from Hippocrates, Celsus and other Greek and Roman texts. After the fall of the Roman Empire much of the medical knowledge moved to the Arab world, although with little or no progress in lacrimal surgery. The same holds true for the middle ages and the renaissance ${ }^{[1]}$. The modern era of lacrimal surgery begins in the early 18th century. In 1724 Platner described the procedure in which a golden cannula was inserted through the lacrimal punctum. In 1904 Toti published his report on surgical treatment of dacryocystitis, which was a significant step in the development of DCR ab externo ${ }^{[2]}$ Killian described the first intranasal approach to DCR in1889. Transnasal endoscopic DCR (TE-DCR) was first performed by Caldwell in 1893, but was soon abandoned due to difficult visualization and numerous complications ${ }^{[3]}$. However, with the advent of new technology permitting better visualization used in endoscopic sinus surgery, TE-DCR has been revived [7]. The advantages of TE-DCR over external DCR are: ( 4 ) no skin incision with a resulting scar, ashorter procedure time and patient recovery period. Due to the above mentioned advantages over the classical approach, TE-DCR has become the treatment of choice for obstructions at the level of lacrimal sac or nasolacrimal duct and a revision procedure for failed classical DCR. The last step in the development of a less traumatic
Dr. Ahmed Dawood Jasim

Ninavah Health Directorate, Iraq 
DCR is the Endocanalicular / transcanalicular approach. In this approach, first described in 1963 by Jack, a probe is inserted through the lower lacrimal punctum via the canaliculus into the lacrimal sac following the anatomical pathway of tear outflow [5]. Osteotomy is performed either by a mechanical drill or delivery of laser energy through an optic fiber, which is inserted within the probe. Advantages of laser surgical technique over mechanical DCR techniques include: precise cutting and removal of tissue by thermal effect, minimal trauma to adjacent tissue, and above all, the possibility to perform the procedure through an anatomical pathway. The first cadaveric studies in the early 1990's proved that osteotomy of lacrimal bone can be achieved by means of laser energy delivered through an optic fibre by transnasal or transcanalicular approach ${ }^{[6]}$. The prefixes endo- or trans are used as synonyms and mean insertion of an optic fiber inside the lumen of the lacrimal canaliculus and Sac. The authors suggest the term transcanalicular laser DCR, TCLDCR in short, because the endoscopies not inserted into the lumen of the canaliculus, but the obstruction is by passed across (Trans) the medial wall of the lacrimal sac and not by opening the lumen of the nasolacrimal duct itself, as the prefix endo implies. The first laser described for clinical use in DCR procedure was the KTP laser in 1993, ${ }^{[7]}$ followed by the use of Ho: YAG laser and the Nd: YAG laser in the period from 19941998, either with a TE-DCR or TCL-DCR ${ }^{[8]}$. The first descriptions of a TCL-DCR with an Er: YAG laser date back to the years 1997 and $1998^{[9]}$. The use of a diode laser for TCLDCR was first reported in 2000, and later in $2004{ }^{[10]}$. Diode laser assisted DCR is the topic of several current papers, and this laser seems to offer specific advantages for DCR [11]. The main technical obstacle in TCL-DCR is the delivery of a sufficiently powerful laser beam via a relatively narrow optical fiber, which in turn fits into an endocanalicular probe. Several laser wavelength successfully comply with this requirement. Yet there are other considerations to take into account, mainly unwanted collateral heating of the probe and residual thermal damage to the target tissue. The purpose of this prospective study was to analyze the success rate of TCL-DCR with a $980 \mathrm{~nm}$ diode laser on a series of 68 successive procedures. Causes of nasolacrimal duct obstruction include the following:

1. Involutional stenosis: is probably the most common cause of NLD obstruction in older patients. It affects women twice as frequently as men.

2. Dacryolith: Can also produce NLD obstruction and consist of shed epithelial cells, lipids and amorphous debris with or without calcium.

3. Sinus disease: Often occurs in conjunction with, and in other instances may contribute to the development of NLD obstruction.

4. Trauma: Naso-orbital fractures may involve NLD, rhinoplasty and endoscopic sinus surgery may lead to NLD obstruction.

5. Inflammatory disease: Granulomatous disease, including sarcoidosis, Wegener granulomatosis and lethal midline granuloma, may also lead to NLD obstruction.

6. Lacrimal plugs: As with similar cases of canalicular obstruction, dislodged punctual and canalicular plugs can migrate to and occlude the NLD.

7. Radioactive iodine: Therapeutic radioactive for the treatment of thyroid cancer may also lead to closure of NLD.

8. Neoplasm: Neoplasm should be considered in any patient presenting with NLD obstruction ${ }^{[12]}$. The lacrimal system consist of superior and inferior puncta, which turn in to superior and inferior canaliculi, which then join in to the common canaliculus, this region is known as the upper lacrimal system. The common canaliculus turns in to the nasolacrimal sac which is about 12-15 long which is eventually narrows in to the nasolacrimal duct which is about $18 \mathrm{~mm}$ long and that eventually empties in to the inferior meatus, the sac and the duct comprise the lower lacrimal system.

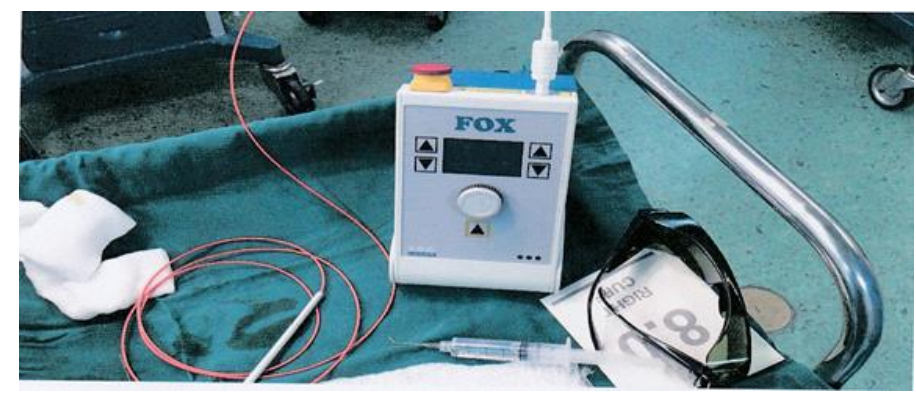

$980 \mathrm{~nm}$ FOX diode laser

Advantages of TCL-DCR:

1. Local and general anesthesia.

2. Minimal invasive.

3. Fast recovery.

4. Good hemostasis, fast 4. Simple change of accessories. postoperative recovery.

5. Preservation of lacrimal pump 5. Unbeatable price. anatomy.

6. Fast treatment.

\section{Technical data of diode laser}

\begin{tabular}{|c|c|}
\hline LASER & Diode \\
\hline Wavelengths, output power & $\begin{array}{c}980 \mathrm{~nm},>9 \mathrm{Watt} \\
810 \mathrm{~nm}, 7 \mathrm{Watt}\end{array}$ \\
\hline Pulse length & $1 \mathrm{~ms}$ to $\mathrm{cw}$ \\
\hline Pulse interval & $2 \mathrm{~ms}$ to $1 \mathrm{Sec}$. \\
\hline Aiming beam & Diode $(\mathrm{red}) 650 \mathrm{~nm}, 2 \mathrm{~mW}$ \\
\hline Dimensions $(\mathrm{W} \mathrm{m} \mathrm{mH})$ & $12 \mathrm{x} 21 \mathrm{x} 10 \mathrm{~cm}$ \\
\hline Weight & $1,2 \mathrm{~kg}$ ready to use \\
\hline Power requirement & Rechargeable batteries \\
\hline
\end{tabular}

\section{Patients and Methods}

Sixty six patients with complete obstruction of NLD, 2 of them had bilateral NLD obstruction with age range (5-55) years were included in the study, they were underwent transcanalicular laser dacryocystorhinostomy in the period from October 2012January 2013at Al Mosul Teaching Centre. A complete ophthalmic examination was performed to rule out other causes of watery eyes: blepharitis, ectropion, entropion, lagophthalmos, trichiasis, conjunctivitis, conjunctivochalasis, keratitis. A Jones dye test was performed and irrigation of the lacrimal pathways. A rhinologic examination was performed to rule out concomitant nasal pathology, e.g. septum deviation, concha bullosa, nasal polyposis. Patients with concomitant nasal pathology were first referred for rhinologic treatment. An informed consent was obtained by the patients. A $980 \mathrm{~nm}$ diode laser was used in repetitive pulse mode. The laser settings were: 
power $10 \mathrm{~W}$, pulse length $90 \mathrm{~ms}$ and pause between pulses 50 ms. Laser light was delivered through a $0.2 \mathrm{~mm}$ optic fibre, which in turn was inserted into a canalicular probe with an irrigation channel. The procedure was performed under general anesthesia in most of the patients in the study and under local anesthesia in some patients. The nasal mucosa of the lateral nasal wall was packed with gauze soaked in $1 \%$ tetracaine solution or other nasal decongestant (Naphazoline) and infiltration with a solution of epinephrine 1:100.000. The site of osteotomy was determined (Just anterior and inferior to the attachment of the middle nasal concha) by looking into the nasal cavity with speculum or endoscope and simultaneous transillumination of the lateral nasal wall from the side of the sac. An infraction of the middle nasal concha was done in cases of limited view. Osteotomy was achieved by applying the laser beam via an optic fibre, which inserted into the lacrimal sac with a probe. Irrigation with $0.9 \%$ saline solution of the endocanalicular probe was used to prevent overheating of the probe. The size of osteotomy was controlled using a nasal speculum endoscope. Once an opening of at least $5 \mathrm{~mm}$ in diameter was achieved, application of laser energy ceased. The next step in the procedure consisted of intubation with a bicanalicular silicone stents in all the following procedures. Packing of the nasal cavity was performed in case of mucosal bleeding. Post-operative treatment included systemic antibiotics (Cefixime, oral), analgesics for 5 days with DexamethasoneNeomycin-Polymyxin B (Maxitrol, Alcon) eyedrops and nasal drops three times daily for three weeks on the treated side as well as $0.9 \% \mathrm{NaCl}$ six times daily for six weeks applied to the nose on the treated side. Follow-up examinations were scheduled for the first day, second day, first week postoperatively, 3-4 months after surgery when patient felt better, silicone tubings were removed after cutting the " $U$ " loupe band at medial canthus. Patency of the nasolacrimal duct was determined as absence of epiphora and/or successful irrigation of the lacrimal passages. The procedure time (Defined as the time from packing of nasal mucosa to the fixation of silicone stents) and the total amount of laser energy.

\section{Procedure}

After proper painting and draping, lower punctum was dilated with dilator and then lower canaliculus was also gently dilated using different size of lacrimal probes (Figure 1). Laser fiber optic cord was passed through tunnel of blunt tipped $21 \mathrm{G}$ and 9 $\mathrm{mm}$ long spinal needle (Figure 2). It was then gently introduced through lower canaliculus into the sac until some resistance by bone was felt. Meanwhile, an ENT surgeon, who introduced endonasal scope with CCTV camera, identified and cleaned the middle turbinate. When the fiber probe reached close to the bone, laser shots were fired intermittently till a small opening was created as seen by an ENT surgeon so as to make sure the correct position of the opening in the superoanterior part of the attachment of middle part of turbinate (Figure 3). By gentle to and fro movements of the needle, fiber optic end could be seen as lighted end through the nasal mucosa. Laser energy was used only for couple of minutes to create an opening. The $980 \mathrm{~nm}$ laser is particularly suited to this procedure as it has high absorption in water and oxyhemoglobin, causing rapid vaporization of the bone and mucosal tissues, while ensuring that there is no bleeding. It has many times the water absorption of $810 \mathrm{~nm}$ wavelength, as well as more absorption in oxyhemoglobin than the $1064 \mathrm{~nm}$ wavelength. The opening was gently enlarged by giving some more laser shots on the margin (Figure 4). Charred tissue pieces were removed with the help of suction by the ENT surgeon. It was also made sure that there was no bleeding. Syringing was done to make sure that the passage was Patent. Then one probe with silicone tube was introduced through lower punctum and allowed to pass through the lacrimal passage till its ends was seen protruding in the nasal cavity. It was gently pulled out with artery forceps by an ENT surgeon (Figure 5). Similarly another probe was fashioned through upper punctum. This would give $U$ loupe of tubings near medial canthus. Both probes were cut and removed Silicone tubes were tied more than 2 to 3 times and placed in the nasal cavity in such a way that they would not give discomfort to the patients (Figure 6). Moreover, their ends would not slip or accidentally pulled out by patients.

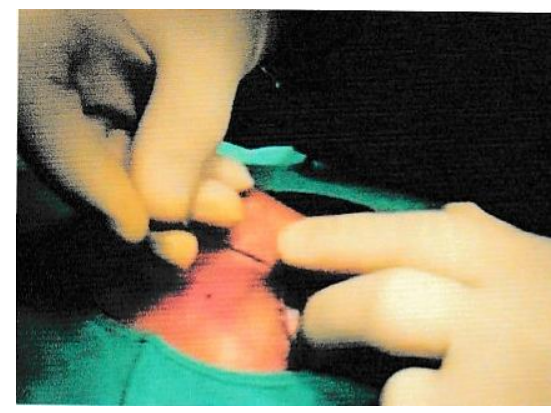

Fig 1: Probing the puncti

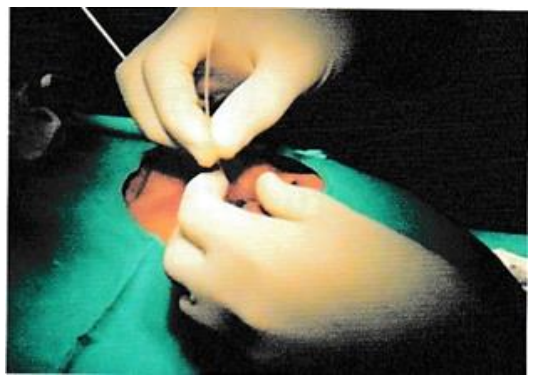

Fig 2: Dilating the canaliculi

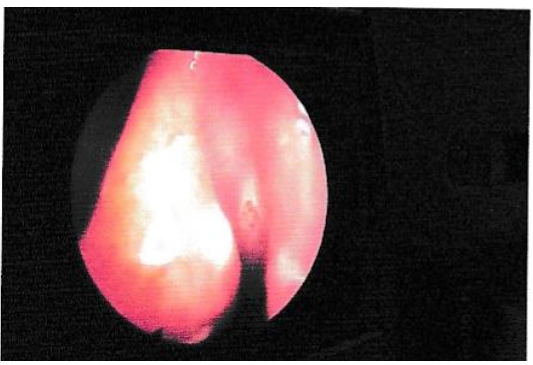

Fig 3: Lateral nasal wall opening

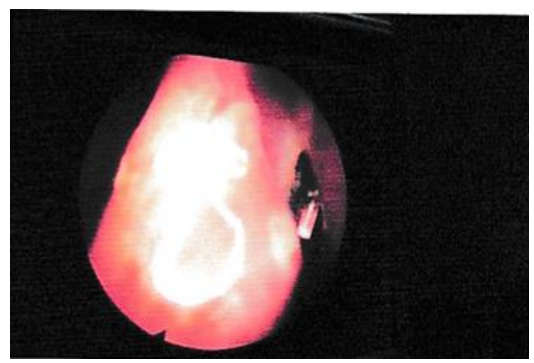

Fig 4: Enlarging the osteotomy 


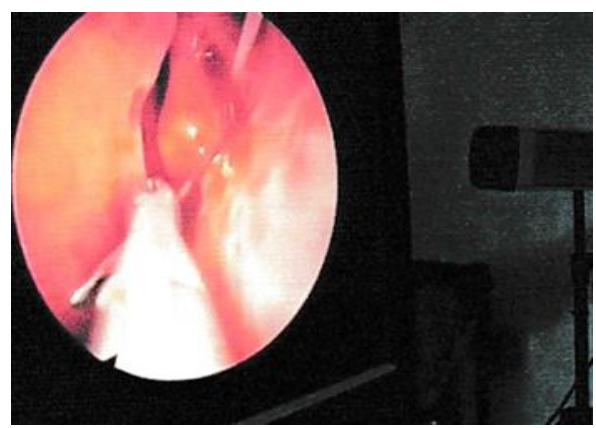

Fig 5: Pulling the probe with silicone tube

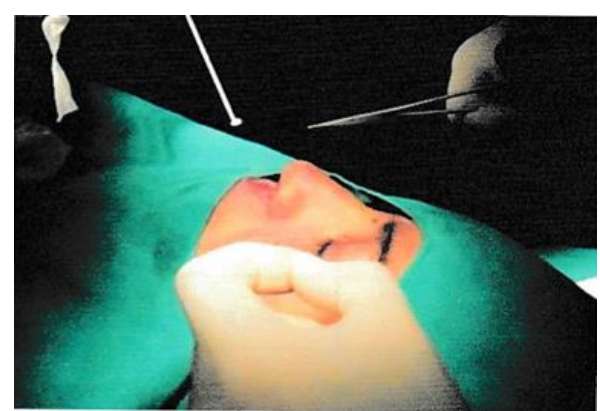

Fig 6: Tying the silicone tube with nasal packing

Table 1: Shows the distribution of age, gender \& involved side of our patients.

\begin{tabular}{|c|c|c|c|c|c|c|c|}
\hline \multirow{2}{*}{$\begin{array}{c}\text { Ages } \\
\text { Years) }\end{array}$} & \multirow{2}{*}{$\begin{array}{c}\text { Total } \\
\text { No. of eyes }\end{array}$} & \multirow{2}{*}{$\mathbf{M}$} & $\mathbf{F}$ & \multicolumn{3}{|c|}{ No. Of patients Unilateral } & \multirow{2}{*}{$\begin{array}{c}\text { No. Of patients } \\
\text { Bilateral }\end{array}$} \\
\cline { 5 - 8 } & & & & $\mathbf{R}$ & $\mathbf{L}$ & Total & 0 \\
\hline $1-10$ & 3 & 0 & 3 & 0 & 3 & 3 & 1 \\
\hline $11-20$ & 16 & 6 & 9 & 7 & 7 & 14 & 0 \\
\hline $21-30$ & 12 & 4 & 8 & 6 & 6 & 12 & 0 \\
\hline $31-40$ & 21 & 7 & 14 & 9 & 12 & 21 & 0 \\
\hline $41-50$ & 9 & 2 & 7 & 2 & 7 & 9 & 1 \\
\hline $51-60$ & 7 & 2 & 4 & 2 & 3 & 5 & 2 \\
\hline Total & 68 & 21 & 45 & 26 & 38 & 64 & \\
\hline
\end{tabular}

\section{Results}

From October 2012 to April 2013, 68 successive TCL-DCR Procedures was performed with silicone stent intubation in 66 patients; 2 patients underwent bilateral procedures. There were 45 females and 21 males with age range (5-55yrs). The average procedure time was 15 minutes (Range 12-35 minutes). The average total amount of delivered laser energy to produce a 5 mm wide osteotomy was $205 \mathrm{~J}$ (Range 170-685). The results: swelling of the ipsilateral lower eyelid 38 cases, postoperative adhesions in 11 patients and bruising in 8cases. The swelling usually resolved in a day or two, and bruising was visible for approximately a week. Removal the silicone stents on average 3 4 months after surgery. No other complications were noted the patients were re-examined at the end of the study (April 2013), the average follow-up time was 3-4 months. Absence of epiphora and patent nasolacrimal duct on irrigation in (55) out of (68) treated eyes. This yields a success rate of $81 \%$

Table 2: Shows the results and complications of TCL-DCR in this study.

\begin{tabular}{|c|c|c|c|c|}
\hline Age (Y) & NO. & Complications & Success & Failure \\
\hline $1-10$ & 3 & 0 & 3 & 0 \\
\hline $11-20$ & 16 & $2(\mathrm{AD})+10(\mathrm{LLS})+2($ Bruises $)$ & 14 & 2 \\
\hline $21-30$ & 12 & $4(\mathrm{AD})+8(\mathrm{LLS})+1($ Bruises $)$ & 7 & 5 \\
\hline $31-40$ & 21 & $3(\mathrm{AD})+11(\mathrm{LLS})+1$ Bruises & 17 & 4 \\
\hline $41-50$ & 9 & $2(\mathrm{AD})+5(\mathrm{LLS})+2($ Bruises $)$ & 7 & 2 \\
\hline $51-60$ & 7 & $4(\mathrm{LLS})+2($ Bruises $)$ & 7 & 0 \\
\hline Total & 68 & 11(AD)+38(LLS)+8 (Bruises) & 55 & 13 \\
\hline
\end{tabular}

\section{Discussion}

The aim of development in the field of DCR is to shorten the procedure time, to shorten patient recovery period, to decrease complication rate, to avoid surgical skin and mucosal scars, and to make the procedure possible on an outpatient basis, under local anesthesia". On the other hand, classic external approach with a 90-95\% success rate remains the golden standard, compared to the $80-85 \%$ success rate of transnasal DCR procedures and 70-80\% success rate of transcanalicular laser DCR [13, 14]. TCL-DCR is a minimally invasive surgical procedure. It takes advantage of accessing the operating field through anatomic pathways the lacrimal canaliculus. This contributes greatly to minimize trauma to the surrounding tissue and avoiding necessary surgical skin scars. The procedure has a fast learning curve and it is even easier to learn than the classical or TE-DCR. However. As in all endoscopic surgeries, the surgeon must have mastered the classical approach first, to be able to use it in the case of intraoperative complications. Of course, the rearecertaindisad vantages of this procedure, such as handling of the laser and the costs of it. A second endoscope for endonasal control as well as basic rhinologic surgery training are strongly recommended. One of the main open questions is adequate osteotomy size, as restenosis at the site of osteotomy is one of the leading causes of long-term failure in DCR ${ }^{[15]}$. An osteotomy of more than $10 \mathrm{~mm}$ in diameter can be routinely achieved by the classic approach, and a slightly smaller osteotomy of 7-9 $\mathrm{mm}$ is achieved by a transnasal approach ${ }^{[13]}$. The osteotomy size in our series was $5 \mathrm{~mm}$ on average. We believe this insufficient when using this technique, as there is minimal trauma to the surrounding mucosa and connective tissue, resulting in less postoperative mucosal scarring. An interesting CT study by Yazici and Yazici showed that the final nasal ostium size 6 months after surgery is in no correlation with osteotomy size at the time of surgery and suturing of mucosal flaps, measuring from 3.1 to $3.8 \mathrm{~mm}$ in width ${ }^{[16]}$. Other factors beside osteotomy size must play a more important role in the development of restenosis, and we believe this to be tissue trauma with subsequent inflammatory response and scarring. 
The patients from this study reported little or no postoperative pain and were discharged at the same day of surgery, which is a great advantage over classical DCR. The extent of eyelid swelling and bruising was also significantly lesser than in classical or endonasal DCR. The success rate of transcanalicular diode laser DCR in this study is among the highest reported for any DCR procedure other than classical DCR [11, 17, 19]. We explain this by minimal trauma to tissue, which results in minimal postoperative inflammation and scarring. Additionally, 1ncases of restenosis, the procedure can be easily repeated, as there is no scarring of the lacrimal path ways or alterations in the anatomical relations. Some studies suggest, that in the future this procedure could even be performed under local anaesthesia [20, 21].

\section{Conclusion}

The $980 \mathrm{~nm}$ TCL-DCR with bicanalicular intubation is a recent Contribution to the developments in the field of lacrimal surgery in AL- Mosul center. It is a minimally invasive and quick procedure, yielding results comparable to classic DCR, and is better than TE-DCR procedure. It facilitates a short patient recovery period, a shorter procedure time and avoidance of a skin scar. In the future, the procedure can be performed under local anesthesia, on an outpatient basis. Absence of epiphora and a patent nasolacrimal duct on irrigation in (55) out of (68) treated eyes. This yields a success rate of $81 \%$.

\section{References}

1. Hughes SM. Te history of lacrimal surgery. Adv Ophthal Plastic \& Reconstructs. Surgery. 1986; 5:139-68.

2. Toti A. Nuovo metodo conservatore di cure radicaled elle supporazi on icronichedel saccolacrymale. Clin Med Firenze 1904; 10:385-9.

3. Caldwell GW. Two new operations for obstruction of the nasal duct with preservation of the canaliculi. Am J Ophthalmol 1893; 10:189.

4. Malhotra R, Wright M, Olver JM. A consideration of the time taken to dacryocystorhinostomy (DCR) surgery. Eye 2003; 17:691-6.

5. Jack MK. Dacryocystorhinostomy. Description of a transcanalicular method. Am J Ophthalmol. 1963; 56:9747.7 .

6. Massaro BM, Gonnering RS, Harris GJ. Endonasal laser dacryocystorhinostomy. New approach to nasolacrimal duct obstruction. Arch Ophthalmol. 1990; 108:1172-6.

7. Reifer DM. Results of endoscopic KTP laser-assisted dacryocystorhinostomy. Ophthal Plast Reconstr Surg. 1993; 9:231-6.

8. Piaton JM, Limon S, Ounnas N, Keller P. Transcanalicular endo dacryocystorhinostomy using Neodymium: YAG laser. J Fr Ophtalmol. 1994; 17:555-67.

9. Emmerich $\mathrm{KH}$, Lüchtenberg $\mathrm{M}$, Meyer-Rüsenberg HW, Steinhaue J. Dacryoendoscopy and laser dacryoplasty: technique and results Klin Monatsbl Augenheilkd. 1997; 211:375-9.

10. Eloy P, Trussart C, Jouzdani E. Collet S, Rombaux P, Bertrand B. Transcanalicular diode laser assisted dacryocystorhinostomy. Acta Otorhinolaryngol Belg. 2000; 54:157-63.

11. Hong JE, Hatton MP, Leib ML, Fay AM. Endocanalicular Laser Dacryocystorhinostomy. Analysis of 118 consecutive surgeries. Ophthalmology. 2005; 112:1629-33.

12. John Bryan Holds, Warren J. Chang. et al. American Academy of Ophthalmology: Orbit, Eyelids and lacrimal system. 2011; 13:266-267.

13. Olver J. Colour atlas of lacrimal surgery. Oxford: Butterworth-Heinemann; 2002.

14. Mandeville JT, Woog JJ. Obstruction of the lacrimal drainage system. Curr Opin Ophthalmol. 2002; 13:303-9.

15. Linberg JV, Anderson RL, Bumsted RM, Barreras R. Study of intranasal ostiumexternal dacryocystorhinostomy. Arch Ophthalmol. 1982; 100:1758-62.

16. Yazici B, Yaziciz. Final nasolacrimal ostium after external dacryocystorhinostomy. Arch ophthalmol. 2003; 121:76-80.

17. Ressiniotis T. Voros GM, Kostakis VT, Carrie S. NeohC. Clinical outcome of endonasal KTP laser assisted dacryocystorhinostomy. BMC Ophthalmol. 2005; 5:2.

18. Pearlman SJ, Michalos P, Leib ML, Moazed KT. Trans lacrimal transnasal laser-assisted dacryocys -torhinostomy. Laryngoscope. 1997; 107:1362-5.

19. Moore WM, Bentley CR, Olver JM. Functional and anatomic results after two types of endoscopic endonasal dacryocystorhinostomy: surgical and holmium laser. Ophthalmology. 2002; 109:1575-82.

20. Tripathi A, Lesser TH, O'Donne ell NP, White S. Local anaesthetic endonasal endoscopic laser dacryocystorhinostomy: analysis of patients' acceptability and various factors affecting the success of this procedure. Eye. 2002; 16: 146-9.

21. Fanning GL. Local anaesthesia for dacryocystorhinostomy. Current anaesthesia. \& critical care. 2000; 11:306.9. 